\title{
Cold-Formed Steel Beam-Column Joints with Latex Layer Wrapping
}

\author{
P.S.Aravind Raj, R.Divahar, K. Naveen Kumar, K.Rakkshana
}

\begin{abstract}
Columns are the primary element of a structure and are the first element to face the effect of lateral load during an earthquake. To resist such lateral seismic loading high strength and ductile steel frames with higher energy absorption capacity are generally preferred. The nominal ductile capacity of the steel can be boosted up with additional wrapping that could optimize the seismic performance significantly. The present work deals on the behaviour of cold-formed steel beam and cold formed steel column wrapped with latex layers for strengthening. The specimens were subjected to reversed quasi-static cyclic loading to partially simulate the seismic forces. Experimental results shows significant increase in strength capacity of beam-column with latex layer wrapping.
\end{abstract}

Keywords :Seismic, reversal load, Latex wrapping, beam-column joint, composite.

\section{INTRODUCTION}

Structural steel are preferred more that the reinforced concrete in resisting seismic loads because of its ductility nature and fatigue strength. Also steel framed structures are lighter, more flexible and ensure hysteretic energy absorption capacity making them an ideal system for earthquake resistance structures. Under the seismic loading the failures occur at the connections between the beam and column. Hence the beam-column joint need to be strengthened to increase the strength, stiffness and ductility.

Cheng et al studied the moment connections under earthquake load simulation for the rigid frames of steel structures. The groove weld at the beam flange reduced the plastic strain and stress concentration as the result improving the performance. Han et al studied seismic performance of the CFST column applied along with the axial load simulating the practical loading condition. The author concludes with the results obtained that the seismic criteria are found to be superior in the CFSTRC columns. Broderick

Revised Manuscript Received on December 30, 2019.

* Correspondence Author

Dr.P.S.Aravind Raj, Department of Civil Engineering, AarupadaiVeedu Institute of Technology, Paiyanoor, India. Email: aravindraj.civil@avit.ac.in

Dr.R.Divahar, Department of Civil Engineering, AarupadaiVeedu Institute of Technology, Paiyanoor, India. Email: divahar.civil@avit.ac.in

Mr.K. Naveen Kumar, Department of Civil Engineering, AarupadaiVeedu Institute of Technology, Paiyanoor, India. Email: naveen.civil@avit.ac.in

Ms. Rakshana, U.G. Student, Department of Civil Engineering, AarupadaiVeedu Institute of Technology, Paiyanoor, India.

(C) The Authors. Published by Blue Eyes Intelligence Engineering and Sciences Publication (BEIESP). This is an open access article under the CC BY-NC-ND license (http://creativecommons.org/licenses/by-nc-nd/4.0/) et al. investigated the columns with hollow sections and tubes infilled with concrete in lateral loading testing. The performance of the element increased even after multiple reversal loading in inelastic zones by the infill provided within the tubes. Alameddine et al (1991) studied the corner beam-column joint made of high strength concrete at quasi-static reversed lateral loading for various grades of concretes and different shear stress. The reduced shear stress with improved and required confinement at the joints ended up with higher performance and was useful in shifting the hinge zone away from the joint.

In this paper, the effect of latex layers on the strength, ductility, and energy dissipation capacity of the cold-formed steel beam-columns wrapped with latex layers was experimentally studied. Four specimens including with and without latex layer over cold-formed steel beam-column joints were tested. The specimens were tested under reversed quasi-static cyclic lateral loading and lateral load versus lateral displacement behaviour are presented.

\section{METHODOLOGY}

In the course of study of the quasi-static behaviour of the cold-Formed steel beam-column joint wrapped with the latex layer, following stages of study as shown in Fig. 1 were done to arrive at the results.

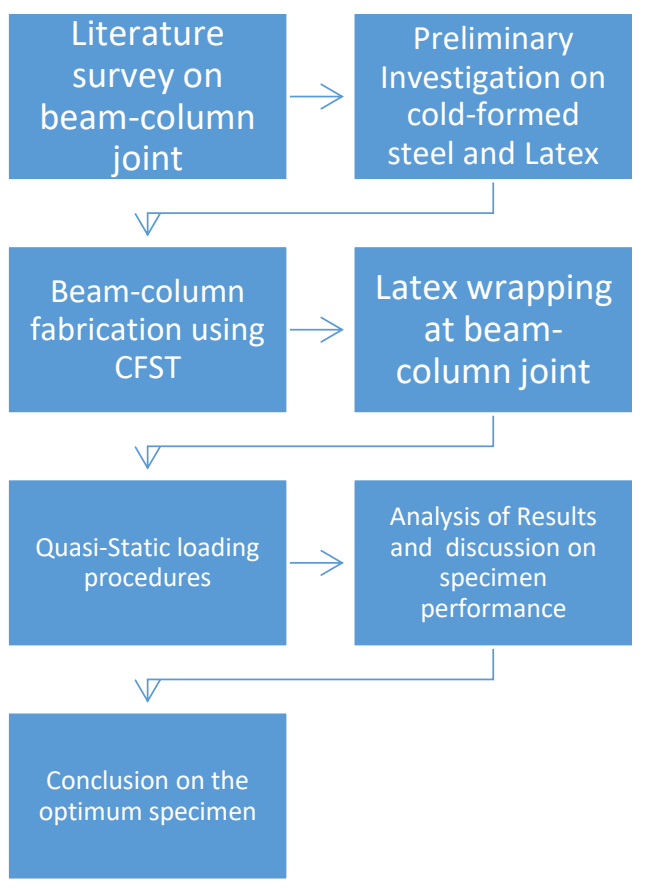

Fig.1 Methodology 


\section{SPECIMEN DETAILS}

Experiments were conducted on fourcold-formed steel frames of height $1200 \mathrm{~mm}$ and beam length of $1500 \mathrm{~mm}$ with the joints welded with cleat angle of $6 \mathrm{~mm}$ thickness. The frame consisted of cold- formed steel square tube section and clod-formed channel sections. Fig. 2 shows schematic view and details of the tested specimens. Two specimens were wrapped with latex layers of $3 \mathrm{~mm}$ each at the beam-column

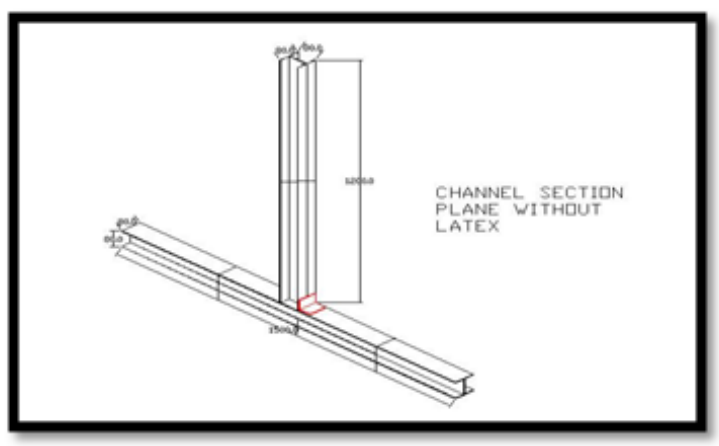

(a) Channel section without latex layers (CS-N)

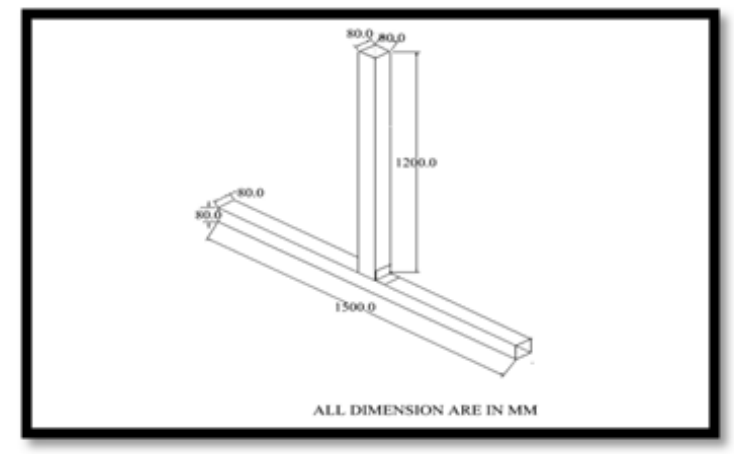

(c) Hollow square tube without latex layer wrapping(HS-N) joint. The wrapped were done for a length of $750 \mathrm{~mm}$ in beam and for a height of $600 \mathrm{~mm}$ in the column from the joint. 'Hemlock' solution was used as the binding compound for the layers with the steel sections. These wrapped systems were steam cured at a temperature of $120^{\circ} \mathrm{C}$ with $3.5 \mathrm{~kg} / \mathrm{cm}^{2}$ pressure. Table 1 shows designation and details of the specimens tested.

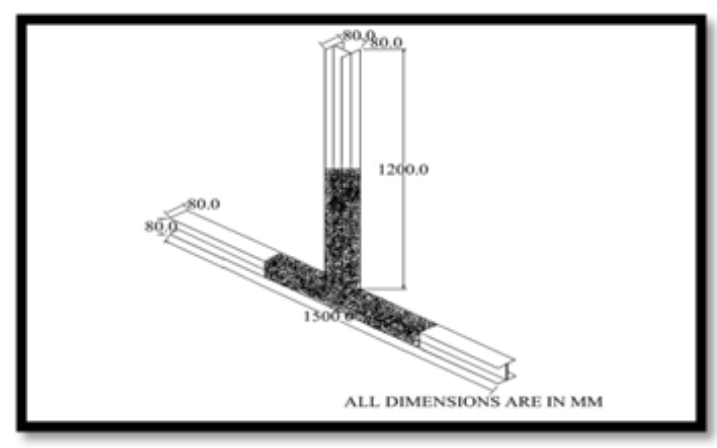

(b) Channel section with latex layer wrapping (CS-W)

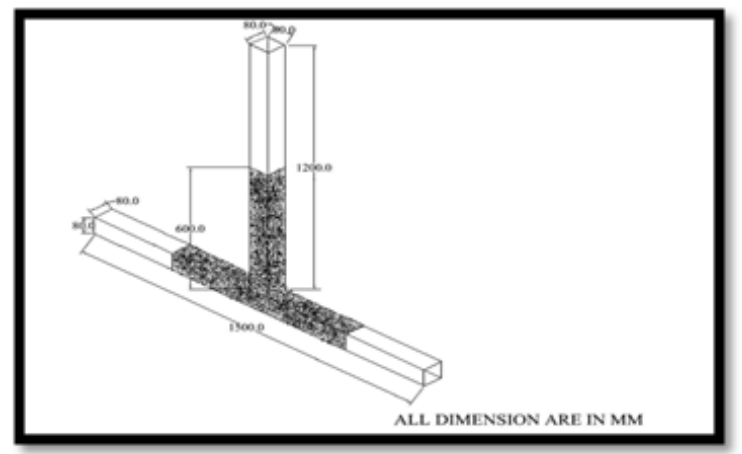

(d) Hollow square tube with latex layer wrapping(HS-W) Fig. 2. Test specimen details of the beam-column

Table I. Details of specimens tested

\begin{tabular}{|c|c|c|c|c|}
\hline Sl. No. & $\begin{array}{c}\text { Specimen } \\
\text { ID }\end{array}$ & Description & $\begin{array}{c}\text { Dimension of } \\
\text { sections (mm) }\end{array}$ & Wrapping of latex sheet \\
\hline 1 & CS-N & Two channel sections & $40 \times 40 \times 3$ & Without latex layer \\
\hline 2 & CS-W & Two channel sections & $40 \times 40 \times 3$ & With latex layer wrapping \\
\hline 3 & HS-N & Square Hollow section & $80 \times 80 \times 3$ & Without latex layer \\
\hline 4 & HS-W & Square Hollow section & $80 \times 80 \times 3$ & With latex layer wrapping \\
\hline
\end{tabular}

\section{EXPERIMENTAL SET-UP}

The specimens are tested under lateral loading with the hydraulic actuator which can laterally apply load to the specimens up to $200 \mathrm{kN}$ with a lateral stoke range of $\pm 100 \mathrm{~mm}$. The hydraulic jack can be reversed to form a cyclic loading pattern. Linear variable displacement transducers (LVDT) is used for measurement of lateral displacement at the column top and a load cell attached to the actuator was used for the measurement of lateral reversed cyclic loads. The experimental set-up is shown in Fig. 3. The beam of the specimen are held up at the base of the loading frame to resist against the uplift created by the lateral load given at the top of the column. And this fixity condition will be supporting the specimen to develop moment at the joint with the lateral load. Also a roller plate arrangement was provided between the top of the column and the vertical jack.to avoid the transfer of drag created by the horizontal jack to the vertical jack. 


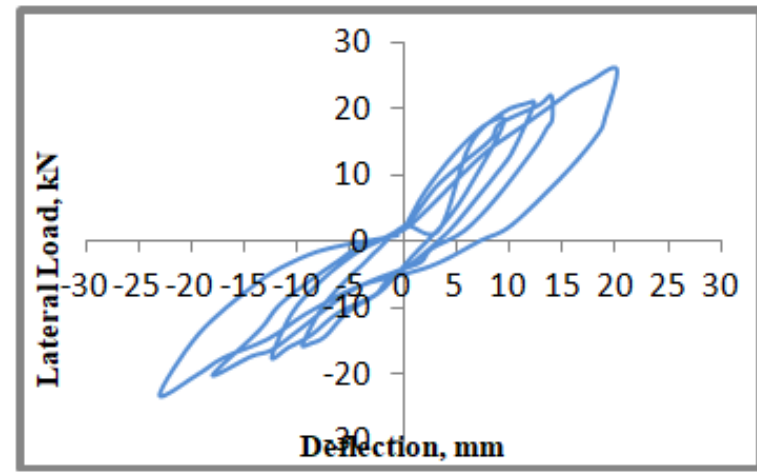

(a) Specimen CS-N

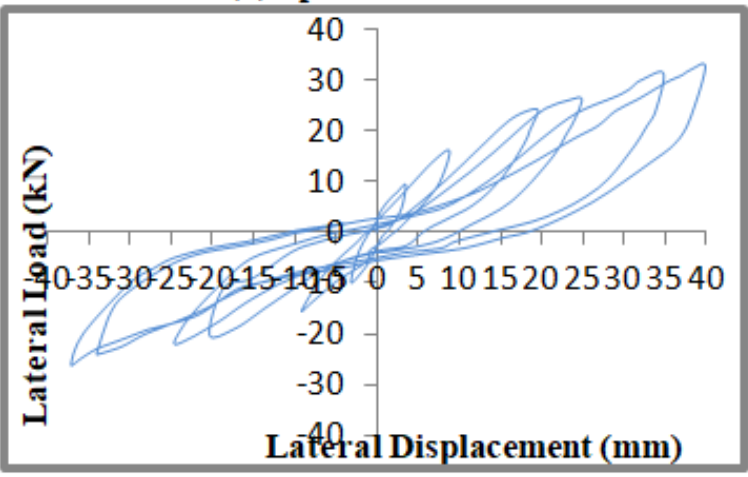

(c) Specimen HS-N

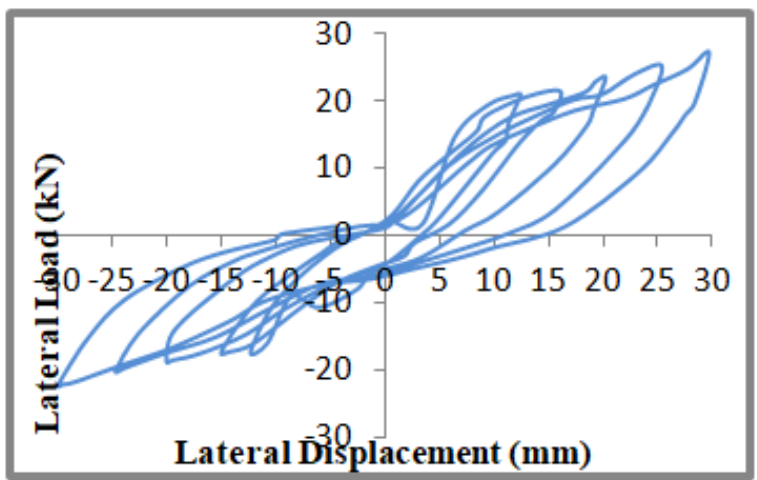

(b) Specimen CS-W

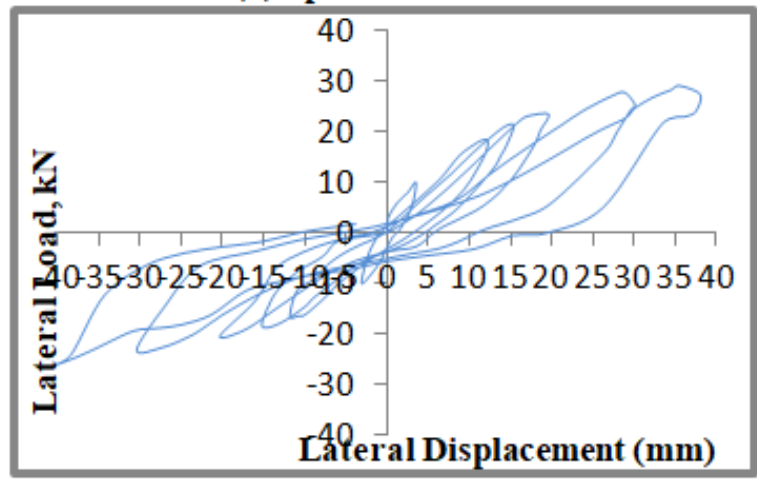

(d) Specimen HS-W

Fig. 3. Hysteresis curve for the specimens

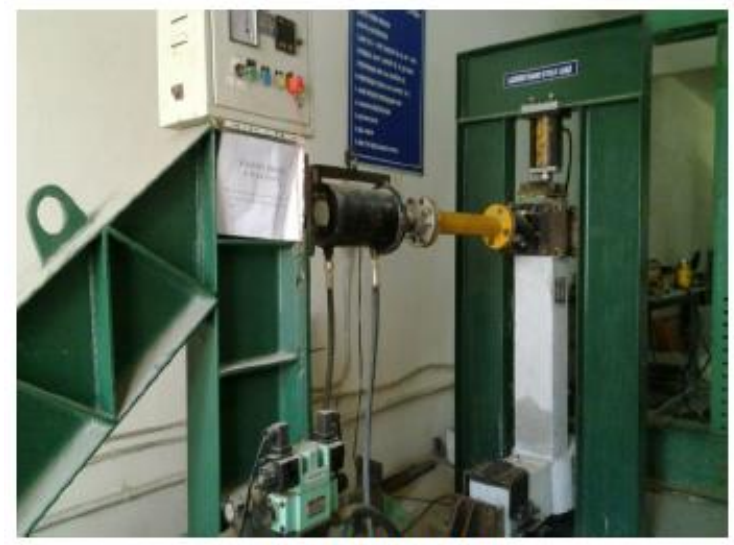

Fig. 3. Test set-up

\section{RESULTS AND DISCUSSIONS}

The hysteresis behaviour of all the specimens from the lateral displacement and lateral load plot is shown in Fig. 3.The specimen CS-N and HS-N failed at a load of $25 \mathrm{kN}$ and $31.3 \mathrm{kN}$ respectively with the corresponding displacement of $21 \mathrm{~mm}$ and $35 \mathrm{~mm}$, and in which the failure occurred at the flange by buckling of the beam section near the beam-column joint. When the system is wrapped, i.e., specimen CS-W and HS-W failed at a load of $27 \mathrm{kN}$ and $33.2 \mathrm{kN}$ respectively with the corresponding displacement, relatively higher than the non-wrapped specimens of $28 \mathrm{~mm}$ and $39 \mathrm{~mm}$. The numbers of cycles that the system with latex layers were also significantly high because of the shift in the buckling occurrence by the wrapping. Fig. 4 and Fig. 5 shows the

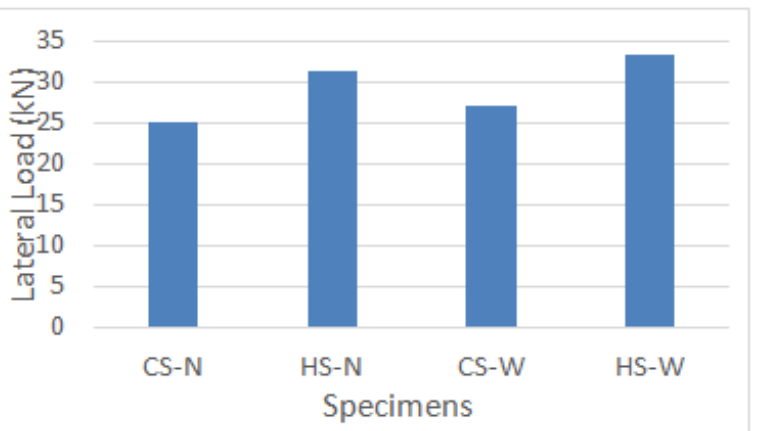

Fig.4 Lateral Load performance of specimens

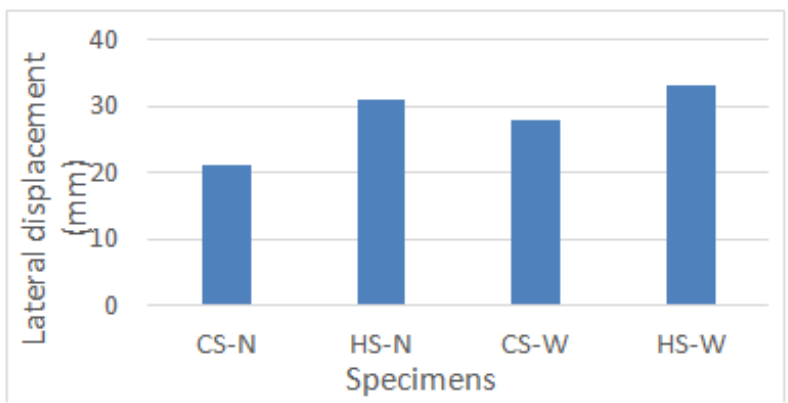

Fig.5 Lateral displacement performance of specimens

\section{CONCLUSION}

An experimental investigation performed to arrive the behavior of cold-formed steel beam-column wrapped with latex layers. Four specimens of cold formed steel beam-columns with and without wrapping were tested under reversed quasi-static cyclic loading and the following conclusions were drawn.

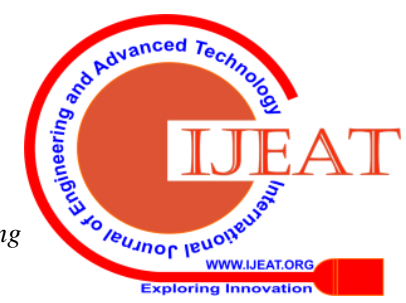


- Lateral load strength capacity of the beam-column joints with two channel sections and wrapped with latex layer is 8 $\%$ more than the beam-column without wrapping.

- The lateral strength capacity of the beam-column joints made with hollow open section and wrapped with latex layer is $6.2 \%$ more than the beam-column without wrapping.

\section{REFERENCES}

1. C. Chich, C. C Lin, C. H. Lin, "Ductile Moment Connection used in Steel Column-Tree Moment Resisting Frames", Journal of Construction Steel Research, 2006, vol. 62(8), pp.793-801.

2. L. H. Han, F. Y. Liao, Z. Tab, Z. Hong, "Performance of concrete filled steel tube reinforced concrete columns subjected to cyclic bending', Journal of Constructional Steel Research, 2009,vol. 65, pp.1607-1616.

3. B. M. Broderick, M.Goggins, A.Y.Elghazouli, "Cyclic Performance of Steel and Composite Bracing Members", Journal of Constructional Steel Research, 2005, vol. 61(4),pp.493-514.

4. F. Alameddine, M. R. Ehsani, "High strength RC connections subjected to inelastic cyclic loading", Journal of structural Engineering, 1991, vol. 177(3),pp 829-850.

5. P. S. Aravind Raj, P. S. Joanna, "Experimental study on reinforced concrete beam and composite column joint with square steel cage", Applied Mechanics and Materials Journal, 2014, vol. 622, pp.81-88.

6. R. Divahar, P. S. Joanna., "Numerical simulation and experimental investigation on static behavior of cold formed steel beam with trapezoidally corrugated web by varying depth-thickness ratio", Asian Journal of Civil Engineering, 2018, 19(8), 121-137.

7. S. P. Sangeetha, P. S. Aravind Raj, "Study on finite element analysis of reinforced concrete beams with GGBS using Ansys", International Journal of Pure and Applied Mathematics, 2018, vol. 118(5), pp.881-887.

\section{AUTHORS PROFILE}

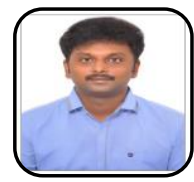

Dr.P.S.Aravind Raj M.E., Ph.D, has completed his doctorate in structural engineering in the year 2015 and has a total research experience of about 8 years. He is passionate on research in the fields of steel-concrete composites, sustainable materials, sustainable structures, etc. He has performed several research on beam-column connection of composite structures. He published and presented his research in many National as well as International conferences and also peer reviewed journals. Currently he is working as Associate Professor in the Department of Civil Engineering, Aarupadai Veedu Institute of Technology, Paiyanoor, Chennai from May 2019.

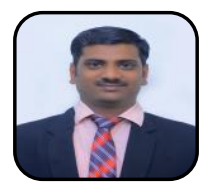

Dr.R.Divahar, was awarded a Ph.D in Civil Engineering (Structural Engineering Specialization) from Hindustan University, India at 2015 and authored a research thesis titled "Behaviour of Cold-Formed Steel Beam with Concrete Encased Trapezoidally Corrugated web. Presently He have more than 9 years of teaching and industrial experience. His inventions are patented and published in India at Jan 2018. He published and presented his research in many National as well as International conferences and also peer reviewed journals. He published more than 25 papers, maximum peer reviewed journal papers was indexed by Scopus, Elsevier, Springer \& Science Citation Indexed. Currently he is working as Associate Professor in the Department of Civil Engineering, Aarupadai Veedu Institute of Technology, Paiyanoor, Chennai from May 2019 onwards. His current area of research is Cold-Formed Steel Structure, Concrete and Composite Structure and Finite Element Analysis

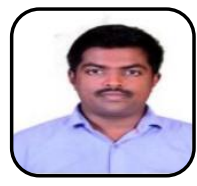

Mr.K.NaveenKumar, complete Graduation in civil Engineering from Mohammed Sathak A.J College of Engineering affiliated to Anna University in the year 2015, Post-Graduation in structural Engineering from Sathyabama University in the year 2017. I have worked as a Planning and Billing Engineer for various project in NAPC Limited. Currently working as Assistant Professor in the department of Civil Engineering on Aarupadi veedu institute of Technology. Has a member in ASCE (American Society for Civil Engineering. 